\title{
Effect of Peptone on the Antifungal Activity of Povidone Iodine
}

\author{
Mohamed Saifeldin Sidahmed ${ }^{1^{*}}$ and Abdel Hafeez Hassan Nimir ${ }^{2}$ \\ ${ }^{1}$ Ministry of Climate Change \& Environment, P.O Box 60, Ras Al Khaimah, UAE \\ ${ }^{2}$ Department of Microbiology, Faculty of Veterinary Medicine, University of Khartoum, Sudan \\ *Corresponding author
}

\section{A B S T R A C T}

\section{Keywords}

Peptone,

Antifungal,

Povidone iodine,

Sabouraud dextrose agar

Article Info

Accepted:

14 November 2020

Available Online:

10 December 2020
This study was conducted in vitro to test the effect of Peptone as one of the protein-rich materials, on the antifungal activity of Povidone Iodine. The Povidone Iodine was tested against two fungi (Candida albicans and Aspergillus flavus) cultured on Sabouraud Dextrose Agar medium which contains peptone, and Potato Dextrose Agar medium as a negative control with the Agar well diffusion method, and the diameters of the inhibitory zones were measured in millimeters. The Povidone Iodine antifungal activity was deactivated against fungi cultured on $\operatorname{SDA}(C$. albicans $=0$ $\mathrm{mm}, A$. flavus $=0 \mathrm{~mm}$ ) while it had maintained its antifungal activity on PDA (C. albicans $=15 \mathrm{~mm}, A$. flavus $=5 \mathrm{~mm}$ ). In conclusion, this in vitro study demonstrated that Peptone can deactivate the antifungal activity of Povidone Iodine.

\section{Introduction}

Since the discovery of Iodine in 1812 by the French scientist Courtois, this element underwent many pharmaceutical improvements as the scientists developed a number of Iodine compounds to overcome its adverse side effects (e.g., its painfulness on open wounds, toxicity, the possibility of allergic reactions etc.) without significant loss of germicidal efficacy (Fleischer and Reimer, 1997). Their endeavors were culminated in Iodophors, such as Povidone Iodine (Polyvinylpyrrolidone Iodine) which was introduced to the pharmaceutical markets in the 1950'sas an antiseptic agent against a broad-spectrum of disease-causing microorganisms (Shelanski and Shelanski, 1956; Siggia, 1957).

The typical applications of Povidone Iodine are: skin antiseptics, scrubs, wound cleansing, minor injury applications, treatment of burns, treatment of ulcers, applications in Gynecology, Dental and Oral use, etc., and these applications usually are furnished with organic materials. 
A number of articles have stated that Povidone Iodine is neutralized in the presence of protein-rich biomaterials. Chaiyakunapruk et al., (2002) stated that blood, serum, and other protein-rich biomaterials can deactivate the germicidal effect of povidone Iodine. In addition, Motai et al., (1992) found that the germicidal activity of Povidone Iodine is retarded in the presence of peptone.

In comparative study between Chlorhexidine and Povidone Iodine as skin antisepsis for blood cultures conducted by Mimoz et al., (1999), they stated that the protein-rich biomaterials of the skin can neutralize the germicidal activity of Povidone Iodine, and they pointed out that the efficacy of Povidone Iodine solution may be improved if several minutes are allowed to lapse between application and venipuncture.

The majority of the available data about the influence of protein-rich materials on the germicidal effect of Povidone Iodine are basics. The antibacterial efficacy of Povidone Iodine like many commercially available disinfectants has been well documented, but very little information exists on their antifungal properties (Cremieux and Fleurette, 1983; Grayson, 1982).

The aim of this study was to investigate the Antifungal activity of Povidone Iodine in the presence of Peptone.

\section{Materials and Methods}

This study was conducted on Povidone Iodine $10 \%$ against 2 fungi, Candida albicans ATCC90028 and Aspergillus flavus obtained from Central Veterinary Researches Laboratories-Soba. The in vitro fungicidal activity was assayed by agar well diffusion method (Kavanagh, 1972). Cultures of
Aspergillus flavus and Candida albicans were grown on Sabouraud Dextrose agar slants, and incubated at $30^{\circ} \mathrm{C}$ (A. flavus) and $37^{\circ} \mathrm{C}$ (C. albicans) for4 days, then fungal spore suspensions were prepared and stored in the refrigerator. One $\mathrm{ml}$ of each fungal suspension was thoroughly mixed with $100 \mathrm{ml}$ of molten sterile Sabouraud Dextrose Agar and Potato Dextrose Agar (as a negative control) which were maintained at $50^{\circ} \mathrm{C}$. Twenty $\mathrm{ml}$ aliquots of the inoculated SDA and PDA were distributed into each sterile Petri dish and left to set. In each of these plates 2 cups (10 $\mathrm{mm}$ in diameter) were cut using a sterile cork borer (No. 4) and agar discs were removed. Alternate cups were filled with 200 microliter of Povidone Iodine $10 \%$ using automatic micro pipette, and allowed to diffuse at room temperature for two hours. The plates were then incubated for 48 hours at $37^{\circ} \mathrm{C}$ for Candida albicans and at $30^{\circ} \mathrm{C}$ for Aspergillus flavus. Two replicates were carried out. After incubation, the diameters of the resultant inhibition zones were measured in millimeters, averages were tabulated.

\section{Results and Discussion}

The antifungal activity of Povidone Iodine was measured on fungi cultured on media contain Peptone (SDA) and other without Peptone (PDA) using Agar well diffusion method.

The antifungal activity of Povidone Iodine yielded no inhibition zone against Candida albicans and Aspergillus flavus growth that were cultured on SDA as shown in table 1. The antifungal activity of Povidone Iodine (10\%) resulted in an inhibition zone against Candida albicans $(15 \mathrm{~mm})$ and Aspergillus flavus $(5 \mathrm{~mm})$ that were cultured on PDA as shown in table 2 . 
Table.1 Diameters of zones of inhibition of Povidone Iodine (in mm) against Fungi on SDA

\begin{tabular}{|l|c|c|}
\hline Fungi & Zone of inhibition (in mm) & Average \\
\hline Aspergillus flavus & 0 & 0 \\
\hline Candida albicans & 0 & 0 \\
\hline
\end{tabular}

Table.2 Diameters of zones of inhibition of Povidone Iodine (in mm) against Fungi on PDA

\begin{tabular}{|l|c|c|}
\hline Fungi & Zone of inhibition (in mm) & Average \\
\hline Aspergillus flavus & 4 & 5 \\
\hline Candida albicans & 6 & 5 \\
\cline { 1 - 2 } & 16 & 15 \\
\hline
\end{tabular}

Figure.1 Sensitivity of the fungi to the antimicrobial activity of Povidone iodine on SDA and PDA (in mm)

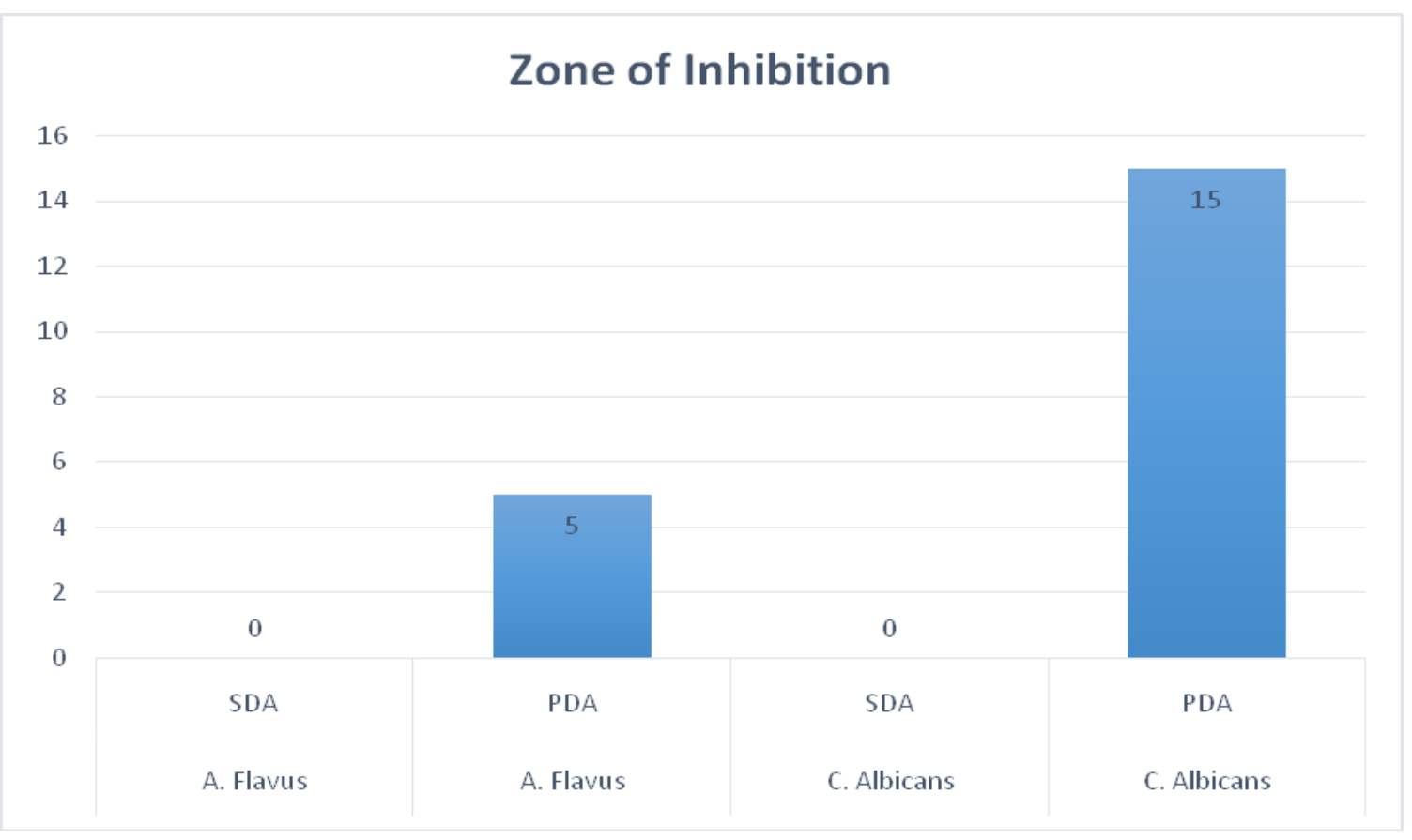

For many years, Iodine has been recognized as an effective broad spectrum germicidal agent. Its adverse side effects have been significantly reduced by using Povidone Iodine (Carroll et al., 1955).The Povidone Iodine is commonly used as the disinfectant of choice in different practices and applications, and practically, the povidone Iodine is one of the most efficient disinfectants. The antimicrobial effect was attributed to the Iodine, which achieve this effect through non-specific mode of action in 
different forms like hydrated molecular iodine $\left(\mathrm{I}^{2}\right)$, hypoiodousacid (HOI) and Iodide ion $\left(\mathrm{I}^{-}\right)$, but in pharmaceutical formulations it is almost entirely attributed to the free molecular iodine (Gottardi, 1972; Rackur, 1985).

This in vitro study investigated the influence of Peptone; as one of the protein-rich materials, on the antifungal efficacy of Povidone iodine.

In the present study, the antifungal activity of povidone iodine was valid on the Potato Dextrose Agar media while it was absent on Sabouraud Dextrose Agar media due to the presence of the Peptone which it is one of the SDA chemical constituents, and this agrees with the work of Motai et al., (1992) and Chaiyakunapruk et al., (2002). This result suggests that the protein-rich materials neutralize the antifungal efficacy of Povidone Iodine likewise the antibacterial activity in the previous studies (Fig. 1). In contrary to Zamora et al., (1985) and Gottardi (1991), they found that in practice, there is no substantial decrease in the antimicrobial efficacy of $10 \%$ Povidone-Iodine preparations are likely with body fluids having a composition similar to plasma. Therefore, these results; like any in vitro findings, should be considered as preliminary findings and should be confirmed under in vivo conditions simulating organic matter load, and with more replication.

In conclusion, this study proved that the presence of the peptone can suppress the antifungal activity of Povidone Iodine in vitro.

\section{References}

Carroll, B., Kevsin, J., and Steinmen, I. D. (1955). The mode of action of Iodine on infectious agents. J Newark Beth-Israel
Hosp. 6(1):129

Chaiyakunapruk, N., Veenstra, D. L., Lipsky, B. A., and Saint, S. (2002). Chlorhexidine compared with povidone-iodine solution for vascular catheter-site care: a meta-analysis. Ann Intern Med, 136: 792-801

Cremieux, A., and Fleurette, J. (1983). Methods of testing disinfectants, In S. S. Block (ed.), Disinfection, sterilization, and preservation, 3rd ed. Lea \& Febiger, Philadelphia. p. 918 945.

Fleischer, W., and Reimer, K. (1997). Povidone iodine in antisepsis - State of art. Dermatology, 195(Suppl 2):3-9

Gottardi, W. (1972). Aqueous iodine solution disinfectants. Zentralbl Fur Bakteriologie and hygiene F. Abt. Orig. B., 167: 206

Gottardi, W. (1991). Iodine and iodine compounds in: Block SS, ed., Disinfection, sterilization, and preservation. 4th ed. Lea \& Febiger, Philadelphia, Pa. p. 152-166.

Grayson, M. (1982). Disinfectants and antiseptics, In M. Grayson (ed.), Antibiotics, chemotherapeutics and antibacterial agents for disease control. John Wiley \& Sons, Inc., New York. Pp. 435-474

Kavanagh, F. (1972). Analytical microbiology .Vol .11.Academic press (pub) New York and London, p11

Mimoz, O., Karim, A., Mercat, A., Cosseron, M., Falissard, B., Parker, F., Richard, C., Samii, K. and Nordmann, P. (1999). Chlorhexidine compared with povidone-iodine as skin preparation before blood culture: a randomized, controlled trial. Ann Intern Med. 131:834-7.

Motai, S., Kurihara, T., Sugita, M. and Kurashige, S. (1992). Relationship between hand-washing activity of disinfectants and in vitro bactericidal 
activity in the presence of peptone. Kansenshogaku Zasshi, 66(11): 15321537

Rackur, H. (1985). New aspects of mechanism of action of Povidoneiodine. J Hosp Infect, 6(Suppl): 13-23.

Shelanski, H. A. and Shelanski, M. V. (1956). PVP-Iodine: History, Toxicity and Therapeutic Uses. J Intern College Surg, 25(6): 727.
Siggia, S. (1957). The Chemistry of Polyvinyl pyrrolidone Iodine. J Am Pharm Assoc, 46(3): 201.

Zamora, J.L., Price, M.F., Chuang, P. and Gentry, L.O. (1985). Inhibition of povidone iodine's bactericidal activity by common organic substances: an experimental study. Surgery, 98(1): 259.

\section{How to cite this article:}

Mohamed Saifeldin Sidahmed and Abdel Hafeez Hassan Nimir. 2020. Effect of Peptone on the Antifungal Activity of Povidone Iodine. Int.J.Curr.Microbiol.App.Sci. 9(12): 1798-1802. doi: https://doi.org/10.20546/ijcmas.2020.912.213 